\title{
Parkour: uma analítica para a educação física à luz da praxiologia motriz
}

\author{
Parkour: an analytics for Physical Education in the light of Motor Praxiology
}

Parkour: una analítica para la educación física bajo la luz de la praxiología motriz

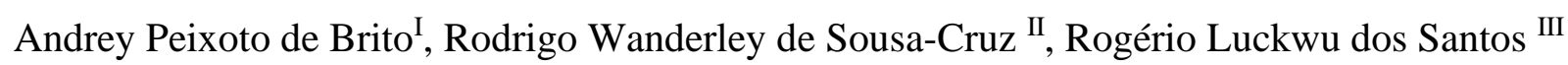

\begin{abstract}
Resumo
O objetivo do estudo é analisar os elementos da lógica interna do parkour para o campo da Educação Física, a partir da Praxiologia Motriz. A investigação é descritiva, com abordagem qualitativa dos dados, do tipo teórica. Foi utilizada a teoria da ação motriz para análise da prática corporal parkour, a partir de suas principais características e singularidades na busca de uma melhor compreensão da sua lógica interna. Acreditamos que o parkour assume uma função relevante na Educação Física no que concerne a sua singularidade desafiadora e autônoma no trato corporal e na ocupação dos espaços, gerando vivências e aprendizagens nos diferentes percursos realizados e ambientes vividos nas situações psicomotrizes, comotrizes e de incertezas quanto ao meio. Concomitante, a Praxiologia Motriz avança na perspectiva de buscar novas e importantes possibilidades de criações e experiências motrizes para a área da Educação Física.
\end{abstract}

Palavras-chave: Parkour; Lógica interna; Educação Física

\begin{abstract}
The aim of the study is to analyze the elements of the internal logic of parkour to the Physical Education field, based on Motor Praxiology. The investigation is theoretical and descriptive, with a qualitative approach to the data. The theory of motor action was used to analyze parkour body practice, based on its main characteristics and singularities in the search for a better understanding of its internal logic. We believe that parkour assumes an important role in Physical Education with regard to its challenging and autonomous uniqueness in the body treatment and in the occupation of spaces, generating experiences and learning in the different paths and environments experienced in psychomotor, co-motor, and uncertain situations regarding the environment. Concomitantly, Motor Praxiology advances in the perspective of seeking new and important possibilities for creations and motor experiences for Physical Education field.
\end{abstract}

Keywords: Parkour; Internal logic; Physical Education

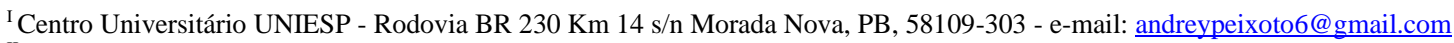

${ }^{\text {II }}$ Centro Universitário UNIESP - e-mail: rodrigosousacruz@gmail.com

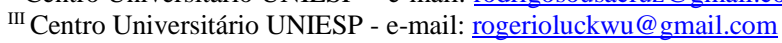




\section{Resumen}

El objetivo del estudio es analizar los elementos de la lógica interna del parkour para el campo de la educación física a partir de la praxiología motriz. Esta investigación es descriptiva con abordaje cualitativo de los datos de tipo teórica. Se utilizó la teoría de la acción motriz para los análisis de la práctica corporal parkour a partir de sus principales características y singularidades en la búsqueda de una mejor comprensión de su lógica interna. Creemos que el parkour asume una función relevante en la educación física en lo que concierne su singularidad desafiadora y autónoma en el tracto corporal y en la ocupación de los espacios generando vivencias y aprendizajes en las diferentes rutas realizadas y ambientes vividos en las situaciones psicomotrices, comotrices y de incertidumbre en relación al ambiente. Concomitante, la praxiología motriz avanza en la perspectiva de buscar nuevas importantes posibilidades de creaciones y experiencias motrices en el campo de la educación física.

Palabras clave: Parkour; Lógica interna; Educación Física

\section{Introdução}

A Educação Física abarca uma riqueza de conteúdos vivenciados por professores, técnicos, alunos, atletas, pesquisadores e praticantes de atividade física e lazer, porém, apesar de uma dominância nos estudos sobre as práticas corporais esportivas ao longo dos tempos, estudos recentes se contrapõem a esse cenário, trazendo à tona preocupações e reflexões acerca de práticas urbanas, dentre elas, o parkour (PK).

O parkour vem sendo estudado sob a ótica filosófica (PEREIRA; HONORATO; AURICCHIO, 2020); sobre o processo de esportivização e espetacularização (CHAGAS; ROJO; GIRARDI, 2015); em parceria com a dança B.boying sob o binômio da cidade e corpo (FREITAS, 2014); fundamentado no conhecimento curricular estadual e nacional (ALVES; CORSINO, 2013); enquanto um fenômeno (sub) cultural (CARVALHO; PEREIRA, 2008). Por isso, neste artigo, pretende-se realizar uma análise praxiológica de práticas urbanas (SARAVI, 2017), uma analítica do parkour.

Sendo inspirado no método natural criado por George Hébert, o parkour partiu da observação dos gestos apresentados por tribos africanas ao lutar, correr e caçar, utilizando o próprio corpo, como seus ancestrais realizavam. Contudo, o título de fundador do parkour acabou sendo agregado ao Francês David Belle que, por sua vez, teve seu pai - o oficial da elite de bombeiros, em Paris - Raymond Belle - como grande referência (ALVES; CORSINO, 2013). A ideia do "PK" consiste em o indivíduo percorrer ou traçar um objetivo utilizando os recursos do próprio corpo, se fortalecendo para agir da melhor maneira possível, independente dos obstáculos que aparecerem no caminho em espaços urbanos, sendo capaz também de conseguir ajudar outras pessoas ou até mesmo salvar alguém.

Por ser uma prática que nasce e se desenvolve na cidade, o parkour faz com que o praticante rompa padrões de movimentação utilizando o ambiente de uma forma diferenciada. Essa vivência faz 
com que o indivíduo desenvolva a criatividade, melhorando sua visão sobre o ambiente, criando novas possibilidades de movimentação (ALVES, 2017). Stramandinoli, Remonte e Marchetti (2012), através de um relevante estudo, conceituam o parkour, embasados em Angel (2011), como uma ação natural através de um mapeamento espacial criativo utilizando apenas o corpo para superar obstáculos em um determinado percurso.

Destarte, torna-se interessante desvelar mais o universo dessa atividade. Para tal, nos fundamentamos na Praxiologia Motriz (PM) - ciência que estuda as ações motrizes que emergem em qualquer situação esportiva ou lúdica, como consequência de uma complexa trama de relações que se estabelecem entre os participantes, independentemente de quem seja (LAVEGA, 2008), dando uma ferramenta relevante de descrição e análise do parkour com vistas nas aprendizagens geradas nas relações com o meio, praticantes e obstáculos. Retrata-se, assim, um fundamental aporte de informações para a área acadêmica em Educação Física, visto o quão necessária é a análise detalhada de uma prática urbana que pode ressignificar os espaços públicos de lazer e a as aulas de Educação Física.

A Praxiologia Motriz, criada por Pierre Parlebas, estuda o conjunto de características e as propriedades estruturais que derivam da organização e relações internas de qualquer prática motriz. Desse modo, a ciência da ação motriz tem como objetivos desvendar a lógica interna de um jogo tradicional ou jogo esportivo, assim como qualquer prática corporal e conhecer suas características estruturais que permitam estabelecer semelhanças e diferenças com outras práticas, bem como averiguar as principais condutas motrizes que se originam segundo os mecanismos de funcionamento de cada prática física, identificando as consequências que originam uma prática motriz sobre a personalidade de seus protagonistas (PARLEBAS, 2001; BORTOLETO, 2008).

Atualmente, o parkour no Brasil é organizado a partir de associações, não sendo, portanto, legalmente reconhecido como esporte, que necessita estar institucionalizado a partir de confederações e federações (CHAGAS; ROJO; GIRARDI, 2015). Corroborando com Parlebas (2013), a esse respeito é necessário apelar para a ciência da ação motriz ou praxiologia motriz.

Primeiro, faz-se necessário o entendimento de que toda atividade motriz competitiva não é necessariamente um esporte. Por exemplo: os jogos físicos que se caracterizam por uma atuação do corpo, por uma encenação de ações motrizes são tratados por comportamentos motrizes informais que não obedecem a nenhum código coletivo; esses comportamentos podem revestir um grande interesse, mas eles remetem, na sua essência, a uma iniciativa individual e à fantasia dos praticantes. As atividades não submetidas a um código aceito são chamadas de "quase jogos"; A Praxiologia motriz trata de todos os 
tipos de práticas ludomotrizes: jogging, nado, acrobacia, rafting, escalada, esportes sobre rodas, saltos, lançamentos (PARLEBAS, 2013).

Segundo, um elemento-chave se impõe constantemente: é a presença de uma competição. Não se trata de uma simples relação companheiro x adversário. Por competição, é necessário compreender uma situação de enfrentamento que regula as interações de oposição e que se acaba pela designação de um vencedor e de um vencido. Parlebas usa a expressão "jogo esportivo". Para ser considerada esporte, a atividade deve ser institucionalizada, ou seja, é preciso que as instâncias sociais tenham-na reconhecido e lhe designado um lugar em sua organização geral, seus calendários, seus grandes encontros nacionais e internacionais (PARLEBAS, 2013).

Como o âmago fundador e atual do parkour é um caminho distinto da esportivização e mais próximo dos desafios e possibilidades que nela engendram, nos interessa uma análise pormenorizada de algumas situações motrizes. Desde a perspectiva da Praxiologia motriz, foram levados a cabo alguns estudos que, apesar de não tratarem especificamente do parkour, investigaram outras práticas urbanas, tais como o skate, basquete, futebol e hockey de rua, observando-se seu funcionamento através de sua lógica interna, em que espaço, tempo e entorno são controlados de modo a uniformizar a prática (SARAVI; BORDES 2016; SARAVI 2019).

Sob a luz da Praxiologia Motriz, buscamos compreender e indicar um possível olhar didático e pedagógico do parkour a partir de sua lógica interna. Para tal, elegemos a seguinte questão-problema: quais os elementos do parkour que podem ser compreendidos pela Educação Física na perspectiva da Praxiologia Motriz? Nessa direção, este estudo objetiva analisar os elementos da lógica interna do parkour para o campo da Educação Física, a partir da Praxiologia Motriz.

\section{Metodologia}

Este estudo caracteriza-se como sendo descritivo, com abordagem qualitativa dos dados, do tipo teórico. Primeiro: descritivo em face de ser uma análise detalhada de como se apresenta em profundidade nossa realidade pesquisada. A possibilidade de descrever as possíveis aprendizagens do parkour e as contribuições para a Educação Física. Segundo: qualitativo para explicar com profundidade o significado e as características de cada contexto em que se encontra o objeto de pesquisa (OLIVEIRA, 2016). Neste estudo adentra-se no contexto da lógica interna, na ação motriz dos praticantes de parkour. Discutir-se-ão as potencialidades que a prática carrega a partir de suas principais características e singularidades para a 
aprendizagem e vivências no campo educacional e do lazer, vista a tão abrangente abstração e riqueza de informações e particularidades existentes, que se fazem pertinentes a serem captados em cada praticante.

Para uma melhor compreensão da sua lógica interna, os dados foram analisados a partir das situações motrizes propostas por Parlebas (2001) e estudadas por diferentes pesquisadores do Brasil (FAGUNDES; FOLLMAN; WENZEL, 2019; RIBAS, 2017; 2014; RIBAS; MARIN, 2013) e do mundo (SARAVI, 2017; LAVEGA, 2008). Nosso enfoque na prática corporal do parkour parte de uma discussão mais aprofundada a partir das situações psicomotrizes e comotrizes; bem como as situações psico-sócio motrizes em um ambiente instável. Abordaremos a seguir as situações psicomotrizes, comotrizes e de incerteza em relação ao meio na prática do parkour, referente às características e relações entre o PK e a PM.

\section{Resultados e discussão}

Após o detalhamento metodológico com os indicadores de análise do parkour para sua compreensão com base na Praxiologia Motriz, faz-se necessário retomar ao estudo de Saravi (2017) para refletirmos que o parkour é uma prática corporal urbana praticada por muitos jovens que se apropriam, transformam e reutilizam os espaços públicos utilizados. Porém, ressaltamos que intencionamos refletir e apontar caminhos de discussão pedagógica para o seio escolar tomando como referência os indicadores escolhidos. Ou seja, partiremos da compreensão da lógica interna do parkour com suas ocorrências em espaços livres para suscitar sua vivência e aprendizado também em espaços fechados na arquitetura, mas possíveis de autonomia, leia-se as aulas de Educação Física.

A partir de um estudo recente sobre a PM com fins didáticos e pedagógicos (FAGUNDES; FOLLMAN; WENZEL, 2019), é possível dialogar com o parkour. Apesar dos autores se deterem às interações sociomotrizes, percebemos que surgem contribuições para a análise no que concerne a suscitar a PM como uma ferramenta de análise e fornecer instrumentos para que o professor (escola) e profissional (lazer) possam aliar ao conhecimento da lógica interna aspectos pedagógicos, metodológicos e didáticos.

Destarte, facilitar condutas mais singulares de cada aluno; provocar ações inteligentes e exitosas; favorecer decisões em funções dos imprevistos; incentivar decifração e leitura do cenário de prática; criar situações de movimento pela improvisação são possibilidades de intencionalidades do professor para garantir aos alunos ou praticantes a aprendizagem. Seja nas áreas de lazer ou nas aulas de Educação Física escolar. 


\title{
3.1 Situações psicomotrizes na prática do parkour
}

Sobre as situações motrizes, Parlebas (2017, p.16) reflete sobre a necessidade do pesquisadorprofessor não cair em ambiguidade:

\begin{abstract}
uma situação que coloca em copresença diferentes atores que não interagem corporalmente no quadro da lógica interna da atividade em causa não é do tipo sociomotor; ela é psicomotriz e, em seguida, corresponde a uma situação dita "comotriz" (corrida de cem metros, salto com vara, amarelinha). Precisamos aprender a desconfiar das aparências e a evitar a armadilha das falsas evidências [...]. Às vezes, as definições situam-se em níveis diferentes e é importante distinguir os campos de significação correspondentes.
\end{abstract}

Como prática psicomotriz, o parkour mantém uma forte interação com o ambiente (espaços e objetos). Dessa relação, é possível gerar aprendizagens a partir de vivências diversas. Conforme estudo de Pereira; Honorato e Auricchio (2020), o parkour é uma prática recente na sociedade e ainda está em formação. De um modo geral, deve-se levar em consideração que sua prática surge de modo espontâneo no tempo livre dos praticantes (em sua maioria jovens) que o fazem de forma auto-organizada. Há uma grande variedade dos ambientes em que são praticados, ao mesmo tempo, em outros espaços mais tradicionais essa prática não ocorre, por exemplo: clubes, academias e ginásios.

De que forma os espaços livres poderiam influenciar espaços fechados para conhecer, praticar, aprender e ampliar novos movimentos com o parkour? A primeira sugestão é valorizar as práticas psicomotrizes como relevantes no processo de vida. São necessárias condutas motrizes que precisem mais do próprio praticante. Que possa entender o ambiente (espaços e objetos) como partícipe do processo de experiência e de aprendizado. Os espaços e objetos fazem parte dos pilares da lógica interna aliados aos jogadores e ao tempo. Fagundes, Follman e Wenzel (2019) nos ajudam a entender o parkour em cada possibilidade de interação do praticante sob a orientação da prática motriz e no auxílio das tramas de relações estabelecidas no sistema praxiológico e análise a partir de um guia didático (2019) e que nos inspira a pensar o parkour para além do lazer, mas com fins pedagógicos.

A partir do conhecimento de sua lógica interna, é possível perceber outras possibilidades de se comunicar com o mundo que o cerca, através de uma prática corporal urbana como o parkour. Parlebas (2001) caracteriza a situação psicomotriz como uma prática que vai manter uma ligação direta com o entorno e influenciar profundamente a percepção e decisão do praticante. Ou seja, no parkour, a codificação do entorno vai ajudar na possibilidade da compreensão individual do meio tanto domesticado (estável) como selvagem (instável). 
As situações psicomotrizes são práticas nas quais há atuação sem companheiro ou adversário, sem a existência, assim, de uma comunicação direta ou indispensável. Bortoleto (2008), fundamentado em Parlebas (2001), reconhece que, em muitas práticas psicomotrizes, é possível aparecer algum tipo de influência entre os participantes durante as práticas motrizes. Nessas situações, os praticantes não agem de forma direta, porém as ações de um jogador podem afetar, desde um ponto de vista estratégico ou emocional, o restante dos participantes. É o caso da comotricidade que veremos a seguir.

\subsection{Possibilidades de situações de comotricidade no parkour}

Situações nas quais há uma copresença de vários indivíduos que atuam na mesma ambiência e que podem influenciar mutuamente os praticantes sem que a ação de um dependa da conduta de outrem, Parlebas denomina-as de Comotricidade. Pode ser de forma alternada e simultânea. A primeira ocorre em momentos distintos. Por exemplo: um praticante de parkour ultrapassa um banco estreito na sua largura, porém de altura significativa para ser vencido. Em seguida, outro realiza a ação. E assim sucessivamente. Dependendo de sua conduta motriz diante do obstáculo, essa ação pode afetar tanto estrategicamente como emocionalmente os demais participantes (BORTOLETO, 2008). A segunda ocorre ao mesmo tempo. Por exemplo: dois praticantes saltam de um ponto baixo (chão) para um ponto alto (escada). Não há comunicação, mas um pode afetar indiretamente ao outro. Dependendo do obstáculo, é possível haver vários atores motrizes concomitantes.

Nas aulas de Educação Física, o professor pode pedagogizar ambas as situações comotrizes com suas turmas a partir dos espaços e materiais disponíveis para a aula, favorecendo aos aprendentes a transmissão voluntária do saber aos menos experientes, a não comparação dos feitos de um aluno sobre o outro, a tentativa de auto superação constante, o fortalecimento corporal para ajudar o próximo, a melhoria da confiança para atingir a precisão do controle do corpo sobre o espaço (PEREIRA; HONORATO; AURICCHIO, 2020).

Podemos analisar também combinações de alguma movimentação ou sequência específica de Flow (capacidade de fluir entre os obstáculos de maneira natural), quando o praticante apenas muda o que estava tentando realizar fazendo com que outros colegas de treino observem e, de maneira automática, imperceptível, mudem o que estavam fazendo. 


\subsection{Situações motrizes em relação à incerteza do meio na prática do parkour}

Sobre o espaço de prática do parkour, há uma relação envolvente com as duas situações já citadas. Primeiro, face às singularidades, pois "utilizam-se corrimões, muros, escadas e restantes obstáculos, numa exploração exaustiva e criativa dos espaços”, conforme entrevista realizada por Carvalho e Pereira (2008, p.438) em estudo com os traceurs, denominação para os praticantes do parkour. Segundo os autores, que mesmo com a inexistência de uma competição organizada, a cada obstáculo superado ou manobra eficiente, os demais tentam realizar. Não por pressões notórias, porém a sensação é de desafio constante (CARVALHO; PEREIRA, 2008).

A relação com o entorno é fonte de dúvida ou incerteza informacional, a qual comporta a necessidade de ler constantemente o espaço de ação, buscando indícios, recebendo informação, processando-a e tomando decisões para adaptar-se de modo ótimo a esse entorno constantemente irregular e flutuante. Trata-se de um meio selvagem ou semidomesticado e incerto. Selvagem por ser um ambiente em grande parte desconhecido. As informações e códigos assumem uma função vital: o praticante precisa se antecipar com os movimentos corporais e interpretar uma pluralidade de dados, evitando percepções errôneas. Semidomesticado por também possuir incertezas, porém com menos surpresas. Há a possibilidade de ter acesso com antecedência ao espaço com indícios, mas sem uma decodificação significativa (PARLEBAS, 2001). O que difere do meio selvagem para o semidomesticado é o grau de incertezas.

A movimentação em locais desconhecidos, onde o praticante está observando pela primeira vez, já no momento da ação em si, é uma situação arriscada, "é como correr no escuro" para muitos, é necessário levar em conta vários aspectos e analisar detalhadamente o ambiente. Se o local desconhecido é plano, abre amplo espaço para visão e adaptabilidade antecipada; se o local não é plano, esconde possíveis surpresas por trás dos muros, como no caso de obstáculos baixos ou bem determinados. Se o local está dotado de obstáculos incertos, inseguros, onde há riscos de desabamento, deslizamento, rachaduras, ou há surpresas, como em locais altos onde ocorrem buracos, abismos, até mesmo umidades, se apresenta perigo quanto à presença de pessoas estranhas, considera-se arriscado, pois necessitará do Traceur (praticante) uma tomada de decisão extremamente rápida, também necessitando de um planejamento prévio e criativo em um prazo de tempo muito mais curto que nos treinos em locais já observados e planejados.

O parkour faz parte de um conjunto de práticas que se apoiam na leitura (decodificação) da informação que procede do entorno, o qual se apresenta constantemente sob as condições diferentes que 
exigem contínua adaptação às decisões, à aventura ou ao risco, à improvisação (LAVEGA, 2008). Anular as incertezas sobre o meio pode caracterizar um risco. As movimentações abrem espaço para milhares de interpretações sobre o entorno, o que resulta em visões diferenciadas em detrimento do movimento a ser executado, mesmo falando de um solo plano e visualmente claro como o da ginástica rítmica ou acrobática.

Assim, podemos ensinar o parkour em diferentes contextos e situações. Isso não impede um diálogo entre os meios que vise aprofundar as características próprias do parkour, compreendendo melhor seu funcionamento e facilitando o ensino no campo da educação física escolar ou tempo livre (SARAVI, 2017). Partindo do conhecimento nas aulas de educação física para uma exploração dos espaços da praça, bairro e cidade em que se vive, surge então a necessidade de abordarmos alguns termos que podem ser levados em consideração para uma perspectiva da aplicabilidade pedagógica do parkour, dentre os quais mencionamos: conduta motriz, inteligência motriz, tomada de decisão motriz e deciframento do entorno.

3.4 O parkour e suas possibilidades de ensino para a Educação Física com elementos da lógica interna

As condutas motrizes podem ser identificadas como a personalização das ações motrizes, na medida em que se estabelecem a partir do sujeito que as realiza em suas histórias, sentidos, significados e afetos. De que forma as aulas podem facilitar as singularidades de cada ação motriz na transposição dos obstáculos? É fundamental que se proponham situações motrizes de forma mais livre com obstáculos simples e com pouco risco. As alturas, estreitamentos, análise para absorções de impacto em diversas dimensões e tipos de espaços (terreno, pátio, ginásio), aplicação de movimentos cada vez executados com maior naturalidade, fluidez nas sequências de um movimento para outro percurso planejado vão favorecer condutas motrizes que ativam a peculiaridade de cada aluno, o que traz significados do contexto em que está inserido. O contexto situado da aula carrega intenções, percepções, motivações, desejos e frustações. A conduta motriz pode desempenhar um papel fundamental para a educação física (PARLEBAS, 2001).

Isso corrobora com Alves e Corsino (2013) no tocante à relação parkour e aulas de educação física. Os autores afirmam que o PK pode ajudar para além da esfera técnica, contudo contribui para as situações simuladas de perigo e habilidades cognitivas e motrizes, levando o aluno a resolver problemas nas aulas com iniciativas em suas ações e reações mais velozes mediadas pelo professor. Como o estudo de Pereira, Honorato e Auricchio (2020), percebeu-se a partir de um entrevistado que não existe uma pessoa ensinando os primeiros passos do PK e que não há um padrão sistematizado de ensino. "Por outro lado, é preciso encontrar didáticas que respeitem os princípios da atividade. Verifica-se que não há uma organização para o ensino" (p.143). Assim, destacamos a proposição de Fagundes, Follman e Wenzel 
(2019) no que concerne à necessidade e relevância da PM para a prática pedagógica da educação física como uma teoria desveladora e como guia para a prática pedagógica:

Com essa compreensão, constata-se que independentemente da abordagem, do método e dos princípios didáticos elegidos, esses elementos precisam ser tematizados, visto que são referentes à própria especificidade das manifestações socioculturais que compõem a EF. Não obstante, esses conhecimentos da lógica interna de cada prática motriz serão desenvolvidos sob a ótica dos princípios pedagógicos, metodológicos e didáticos, os quais serão enfatizados a partir das concepções de Educação Física, mundo e sociedade de cada professor (FAGUNDES; FOLLMAN; WENZEL, 2019, p.13).

De posse do conhecimento da lógica interna, o professor terá mais ferramentas para pedagogizar o parkour dentro e fora da escola.

A Inteligência motriz trata-se da capacidade do praticante de representar e decidir a melhor estratégia de ação nas situações motrizes a partir dos indícios que o meio oferece. Nesse contexto, Parlebas (2001) alerta que a inteligência motriz será posta em prova em maior ou menor grau segundo o ambiente de prática domesticado ou selvagem. A inteligência motriz quanto ao parkour parte de uma melhor análise e programação criativa das movimentações, menor esforço e melhor qualidade de movimento em relação ao ser e agir natural.

O que a vivência na aula de educação física pode ajudar? Eficiência do deslocamento com simplicidade, fluidez e velocidade das progressões (CARVALHO; PEREIRA, 2008) com o uso potencializado das habilidades naturais como: escalar, correr, saltar, andar sobre quatro apoios, equilibrarse (CHAGAS; ROJO; GIRARDI, 2015) aliado a uma posição adequada de membros e tronco, abrindo um maior espaço para criatividade, liberdade e maior possibilidade de se movimentar. Liberdade essa com solicitações de músculos e articulações cada vez mais eficazes, o que se nota numa movimentação bem mais natural e leve, coordenação, mobilidade, equilíbrio e menor exigência energética.

As tomadas de decisão motrizes estão relacionadas com as adaptações e as reações rápidas são pensadas a partir dos intervalos de um deslocamento para outro; velocidades e distâncias; crescimento das durações das ações frente aos obstáculos; acelerações e desacelerações (PARLEBAS, 2001). O praticante analisa, determina uma intenção motriz e a executa gradativamente. No movimento de "MonkeyVault" movimento que ultrapassa um obstáculo com as pernas passando por entre os braços horizontalmente analisa-se o muro em aproximação enquanto o traceur (praticante) corre. Ele determina naturalmente a quantidade de passadas a serem dadas antes que o ultimo pé toque o chão, as mãos tocam o muro, mas algo dá errado naquele momento, as pernas que deveriam passar entre os braços e acima do muro não saíram como planejado, uma das pernas fica um pouco mais abaixo tocando o pé no muro e dando total 
instabilidade e risco ao traceur que executa. Uma tomada de decisão é necessária urgente para que ele não se machuque (ANGEL, 2011; STRAMANDINOLI; REMONTE; MARCHETTI, 2012).

Pensando nas aulas de educação física, o professor pode criar situações motrizes para que os alunos resolvam com decisões resolutivas com movimentos mais simples e próximos do solo, permitindo ganhar força, flexibilidade, agilidade, coordenação, para somente depois enfrentar obstáculos altos e com mais riscos. Permite também que o professor facilite a criação de condutas e sequências com obstáculos para desafiar os alunos (PEREIRA; HONORATO; AURICCCHIO, 2020). O parkour pode se tornar dentro das aulas de educação física uma educação das condutas e decisões motrizes que se manifesta em uma situação original durante um fluxo de ações em uma solução de uma tarefa motriz (PARLEBAS, 2001).

A análise prévia e a leitura do ambiente com antecipação aos problemas traduzem o deciframento do entorno. O parkour, essencial e histórico, foi surgindo aos poucos em praça pública nas cidades de Lisse, Sarcelles e Léon. Nem sempre a praça estava do mesmo estado que no dia anterior, nem ao menos na hora anterior, podendo haver objetos jogados, umidade, arranhões, alguma rachadura nova ou uma folga que ainda não foi vista em alguma estrutura. Toda e qualquer mudança sob o meio a ser praticado tende a influenciar na movimentação a ser feita, reajustes e novas adaptações (ANGEL, 2011; STRAMANDINOLI; REMONTE; MARCHETTI, 2012). No parkour, existem diversas dimensões de altura, estreitamentos, necessidade de força, precisão, exatidão e explosão que passam a ser consideradas no momento das ações motrizes desenvolvidas. O praticante passa a desenvolver a habilidade de decifrar seu entorno de uma forma individual, os degraus e relevos do ambiente não serão mais observados igualmente, uma vez que o traceur já o catalogou como possibilidade de movimentação.

Em determinados casos, a interpretação do ambiente pode passar por atualizações por parte do traceur. A reinvenção e ressignificado do local ou de um obstáculo específico podem fazer parte da prática do parkour. Desse modo, o praticante pode realizar repetidas vezes movimentos para transpor um obstáculo, reavaliar seu movimento e dar novo significado ao conjunto de possibilidades existentes, realizando em seguida movimentos distintos com base no arcabouço de estratégias motrizes que possui. Se o local já foi analisado ao menos uma vez, o risco lesivo cai drasticamente. Também é importante lembrar que se o ambiente for analisado apenas uma vez, as próximas análises a serem feitas do meio serão cada vez menos detalhadas e cada vez mais rápidas, já que ele gradativamente controlou e se adaptou ao ambiente.

Vilalta (2008) nos ajuda a compreender melhor o aspecto da decodificação e sua relação adaptativa com o meio de prática para as aulas de Educação Física. O grau de incerteza depende do nível 
de experiência e habilidade do praticante nesse meio de prática. Mesmo que o ambiente não contenha um volumoso conjunto de informações a serem decodificadas, este pode gerar grande incerteza a um aluno com menos repertório motriz. Da mesma forma, quanto maior o vocabulário motriz de um aluno, menor será o grau de incertezas. Segundo o autor acima, durante a realização de uma atividade de caráter adaptativo, o praticante deve perceber alguns indícios ou sinais que irão favorecer ler a informação contida no meio de prática e prever a situação motriz que se aproxima. Para nós, o grande aprendizado de decodificação das situações motrizes do parkour se refere a aumentar a capacidade de realizar as condutas motrizes com menos riscos de acidentes.

Por conseguinte, Freitas (2014) sugere técnicas para práticas indoor que dialogam entre as ultrapassagens de obstáculos e a capacidade de mover-se em várias direções com impulsão, força e controle da unidade corporal durante os saltos. Sobre a aterrissagem, suscita que, para sair do chão é preciso saber chegar ao chão, diminuindo o impacto, principalmente nas articulações como o joelho e o tornozelo. As formas de queda são variadas, apesar das limitações. "As duas principais são o rolamento, que absorve o impacto transformando em força de rotação; e o tapa no chão, que age dissipando o choque" (FREITAS, 2014, p.87). O autor reflete um ponto bastante interessante sobre a facilidade que outros conhecimentos corporais dialogariam com o parkour: conhecimentos corporais anteriores sobre lutas, artes circenses, danças e ginásticas. Sabemos com isso que são áreas de conhecimento que compõem o campo de ensino da Educação Física e que os alunos devem ter acesso como riqueza motriz.

\section{Considerações finais}

Acreditamos que o parkour pode assumir uma função relevante no campo da Educação Física no que concerne a sua singularidade desafiadora e autônoma no trato corporal e na ocupação dos espaços gerando vivências e aprendizagens nos espaços urbanos e nas aulas de Educação Física escolar.

Concomitante, ao nos debruçarmos na Praxiologia Motriz, avançamos na perspectiva de desvelar inicialmente o parkour em sua lógica interna, buscando conhecer mais e compreender melhor suas características e possibilidades de criação e novas experiências nas situações motrizes. Dessa maneira, este estudo é uma primeira aproximação conceitual e analítica que pode servir para nortear estudos posteriores. Um maior aprofundamento nos estudos sobre a prática do parkour pode vir a culminar em publicações futuras tanto em periódicos, como em trabalhos acadêmicos formais em graduação e pósgraduação. Conseguimos, no entanto, apresentar algumas situações psicomotrizes, comotrizes e de incerteza no meio, como possíveis indicadores pedagógicos. Por conseguinte, buscamos instigar um olhar 
para o parkour com mais informações praxiológicas na perspectiva pedagógica que subsidie o professor de Educação Física que atue no âmbito escolar ou na área do lazer.

\section{Referências}

ALVES, M.A.C. A prática do Parkour como meio de desenvolvimento de força em membros inferiores e superiores no âmbito escolar. Revista Científica Multidisciplinar Núcleo do Conhecimento, Ano 2, v.01,p.483-487, abril de 2017.Disponível em: https://www.webartigos.com/storage/app/uploads/public/588/4ce/934/5884ce9347c95159950514.pdf

ALVES, C.S.R; CORSINO, L.N. O Parkour como possibilidade para a Educação Física escolar. $\begin{array}{lllll}\text { Motrivivência, } & \text { n. } & 41, & \text { p. 247-257, } & \text { dez/2013.Disponível }\end{array}$ em:https://periodicos.ufsc.br/index.php/motrivivencia/article/view/2175-8042.2013v25n41p247

ANGEL, J. M. CinéParkour: a cinematic and theoretical contribution to the understanding of the pratice of parkour. Tese de Doutorado. Brunel University School of Arts PHD Theses, 2011.Disponível em:https://www.semanticscholar.org/paper/Cin\%C3\%A9-Parkour\%3A-a-cinematic-and-theoretical-tothe-of-Angel/72f8b08356e73fee83f7daaace95127cd2e0c9bf

BORTOLETO, M.A.C. A ginástica artística estudada a partir da ótica da praxiologia motriz: reflexões preliminares. In: RIBAS, J.F.M. (Org.). Jogos e esportes: fundamentos e reflexões da Praxiologia Motriz. Santa Maria: Editora UFSM, 2008.

CARVALHO, R.G; PEREIRA, A.L. Percursos alternativos - o parkour enquanto fenômeno (sub) cultural. Revista Portuguesa Ciências do Desporto, v.8, n.3, p.427-440, 2008.Disponível em:http://www.scielo.mec.pt/scielo.php?script=sci_arttext\&pid=S1645-05232008000300012

CHAGAS, R.R; ROJO, J.R; GIRARDI, V.L. O processo de esportivização de uma modalidade: o parkour enquanto prática espetacularizada. The jornal of the Latin American Socio-cultural Studies of Sport, Curitiba, v.5, n.1, p.21-33, 2015.Disponívelem:https://revistas.ufpr.br/alesde/article/view/42368

FAGUNDES, F.M; FOLLMAN, N; WENZEL, V.I. Como identificar a lógica interna das práticas motrizes de interação? Uma proposta de ferramenta da análise a partir da praxiologia motriz. Revista $\begin{array}{lllll}\text { Kinesis, Santa } \quad \text { Maria, } & \text { v.37, } 019 . & \text { Disponível }\end{array}$ em:https://periodicos.ufsm.br/kinesis/article/view/36035

FREITAS, V. Usos da cidade: parkour e b.boyng. Revista Ciêntífica/FAP, Curitiba, v.11, p.79-95, julho/dezembro,

2014.Disponível

em:http://periodicos.unespar.edu.br/index.php/revistacientifica/article/view/1374

LAVEGA, P. Classificação dos jogos, esportes e as práticas motrizes. In: RIBAS, J.F.M. (Org.). Jogos e esportes: fundamentos e reflexões da Praxiologia Motriz. Santa Maria: Editora UFSM, 2008.

OLIVEIRA, M.M. Como fazer pesquisa qualitativa?.7 $7^{\mathrm{a}}$ edição revista e atualizada. Petropólis: RJ, Vozes, 2016.

PARLEBAS, P. Prefácio. In: RIBAS, J.F.M. (Org.) Praxiologia Motriz na América Latina: aportes para a didática na Educação Física. Ijuí: Editora Unijuí, 2017. 
PARLEBAS, P. Prefácio. In: MARIN, E.C; RIBAS, J.F.M. (Orgs.). Jogo tradicional e cultura. Santa Maria: Editora UFSM, 2013.

PARLEBAS, P. Juegos, deporte y sociedad: léxico de praxiologia motriz. Barcelona: Paidotribo, 2001.

PEREIRA, D.W; HONORATO, T; AURICCHIO, J.R. Parkour: do princípio filosófico ao fim competitivo. Licere, Belo Horizonte, v.23, n.1, março de 2020.Disponível em:https://www.researchgate.net/publication/340244059_Parkour_Do_Principio_Filosofico_ao_Fim_Co mpetitivo

RIBAS, J.F.M. (Org.) Praxiologia Motriz na América Latina: aportes para a didática na Educação Física. Ijuí: Editora Unijuí, 2017.

RIBAS, J.F.M. (Org.) Praxiologia Motriz e voleibol: elementos para o trabalho pedagógico. Ijuí: Editora Unijuí, 2014.

SARAVÍ, J.R. Prácticas corporales urbanas y praxiologia motriz: uma experiência pedagógica em taller. Cadernos de Formação RBCE, p.94-102, março de 2017.Disponível em:http://revista.cbce.org.br/index.php/cadernos/article/view/2259/1220

SARAVÍ, J.R. Skate enelGran La Plata : Lógica interna, lógica externa y Educación Física (Tesis doctoral). --Universidad Nacional de La Plata. Facultad de Humanidades y Ciencias de la Educación, 2019.

Disponível em:https://www.researchgate.net/publication/340511109_Skate_en_el_Gran_La_Plata_Logica_interna_lo gica_externa_y_Educacion_Fisica

SARAVÍ, J.R.;BORDES, P. Prácticascorporales urbanas: deportes institucionalizados o prácticas lúdicas? Revista Acción Motriz, v.17, p.62-70, 2016.Disponível em: https://www.researchgate.net/publication/308794037_Practicas_corporales_urbanas_Deportes_institucion alizados_o_practicas_ludicas_Corporal_urban_practices_Institutionalized_sports_or_recreational_practic es

STRAMANDINOLI, A.L.M; REMONTE,J.G; MARCHETTI, P.H. Parkour: história e conceitos da modalidade. Revista Mackenzie de Educação Física e Esporte, v.11, n.2, p.13-25, 2012. Disponível em: http://editorarevistas.mackenzie.br/index.php/remef/article/view/4037

VILALTA, J.M. Praxiologia motriz e as atividades na natureza. In: RIBAS, J.F.M. (Org.). Jogos e esportes: fundamentos e reflexões da Praxiologia Motriz. Santa Maria: Editora UFSM, 2008.

\section{Como citar este artigo}

BRITO, A. P.; SOUZA-CRUZ, R. W.; SANTOS, R. L. Parkour: uma analítica para a educação física à luz da praxiologia motriz. Revista Kinesis, Santa Maria, v.39, p.01-15, 2021.

* O presente trabalho não contou com apoio financeiro de nenhuma natureza para sua realização. 